\title{
SPORTUOJANČIŲ ASMENŲ TEPINGO TESTO REZULTATŲ VERTINIMAS TAIKANT DUOMENŲ GRUPAVIMO METODĄ
}

\author{
Laura Daniusevičiūtè ${ }^{1,2}$, Zenonas Navickas², Jonas Poderyss', Marius Brazaitis' ${ }^{1}$, \\ Irina Ramanauskiené $\dot{\mathbf{e}}^{1,2}$ \\ Lietuvos kūno kultūros akademija', Kauno technologijos universitetas², Kaunas, Lietuva
}

\begin{abstract}
Laura Daniusevičiūtė. Reabilitacijos magistrẻ. Kauno technologijos universiteto Kūno kultūros ir sporto centro, Kūno kultūros katedros vyresn. metodininkè. Mokslinių tyrimų kryptis — neigalių asmenų funkcinès būklès ypatybès ir kaita taikant fizinio poveikio priemones.
\end{abstract}

\section{SANTRAUKA}

Tyrimo tikslas - nustatyti duomenu grupavimo metodo panaudojimo galimybę Tepingo testo metu. Vertinant centrinès nervu sistemos (CNS) darbingumo ir funkcinès büklès rodiklius, plačiai taikomas Tepingo testas. Duomenys registruojami naudojant specialias kompiuterines programas, sukurtas Lietuvos kūno kultūros akademijos (LKKA) Kineziologijos laboratorijoje pagal Ukrainos kūno kultūros universiteto mokslininku parengta CNS funkcinès būklès ir darbingumo rodikliu vertinimo metodikq. Kompiuterinès tyrimu programos pateikia normalizuotas registruojamu rodikliu reikšmes - CNS darbingumo ir funkcinès büklès rodiklius: CNS paslankumo, asimetrijos, nuovargio, bendrojo darbingumo, anaerobinio darbingumo ir anaerobinio darbo talpos reikšmes.

Buvo ištirta 10 sportuojančiu asmenu, kuriu amžius 17-25 metai. Tyrimai atlikti LKKA Kineziologijos laboratorijoje. Visi tiriamieji atliko klasikini 60 sekundžiu trukmès Tepingo testa, milisekundèmis matuojant laiko intervalus tarp atskiru judesiu. Tepingo testo duomenu grupavimas atliktas Kauno technologijos universiteto Taikomosios matematikos katedroje.

Duomenu grupavimo metodas naudojamas tyrimo duomenu tarpusavio panašumams ir skirtumams analizuoti. Turint duomenu sekq — vadinamaja laiko eilutę (matuojant milisekundèmis), po atskiro kompiuterio klaviatūros spustelëjimo atliekamas Tepingo testas. Iš ju galime sudaryti informatyviuosius vektorius, t. y. atlikti duomenu grupavima. Skaičiavimai atliekami priklausomai nuo to, kokios informacijos mums reikia, t. y. po kiek piršto judesio trukmin (laiko intervalu) turi büti grupuojama, kad gautume naudinga informacija. Gave naujus duomenis - vektorius, galime atlikti matematinius veiksmus, t. y. veiksmus su vektoriais, apskaičiuoti koreliacijos koficiento ¿̇verčius. Turédami šio koficiento ìverčius, gauname nauja informacija apie tiriamo asmens individualiu CNS ypatybiu poreiškio visuma, realizuojant motorinius aktus, ir galime palyginti atskiru eksperimentiniu grupiu duomenis.

Tyrimo rezultatai atskleidè, kad grupuojant po du intervalus vertinimo rezultatai nèra išsamiausi. Tačiau grupuojant tris ir daugiau intervalu pastebimas mažesnis rezultatu išsibarstymas, ir tai leidžia tiksliau vertinti tyrimo duomenis ir padaryti tikslesnes išvadas. Taigi išsamesne informacija apie CNS ypatybes, pasireiškiančias Tepingo testo metu, gaunama, kai grupuojami trys intervalai. Grupuojant po keturis ir daugiau intervalu - rezultatu informatyvumas sumažeja.

Raktažodžiai: duomenu grupavimo metodas, centrinè nervu sistema, Tepingo testas.

\section{IVADAS}

$\mathrm{V}$ ertinant sportuojančių asmenu centrinès nervų sistemos (CNS) ypatybes ir organizmo funkcinę būklę, plačiai taikomas Tepingo testas. Yra sukurta iqvairiu Tepingo testo rezultatu vertinimo metodikų. Ukrainos kūno kultūros universiteto mokslininku (Зеленцов, Лобановский, 1998) parengta CNS funkcinès būklès ir darbingumo rodiklių vertinimo metodika iš esmès padidino klasikinio Tepingo testo informacines galimybes. Jeigu klasikinis Tepingo testas vertindavo tik du pagrindinius CNS funkcinius rodiklius (funkcini paslankumą ir nuovargi), tai Ukrainos mokslininku parengtas vertinimas, panaudojant kompiuterinę tyrimų duomenų registravimo programą, jau pateikia normalizuotas registruojamų rodiklių reikšmes, ¿ivertinami šie CNS darbingumo ir funkcinès būklès rodikliai: funkcinis paslankumas, asimetriškumas, nuovargis, bendras darbingumas, anaerobinis darbingumas ir anaerobinio darbo talpa (Emeljanovas ir kt., 2003). 
Naujų tyrimo metodų ir duomenų vertinimo būdų kūrimas ir tobulinimas yra nenutrūkstamas procesas. Nauji tyrimo duomenu analizès ir vertinimo metodai leidžia analizuoti organizmo fiziologinių mechanizmų sinerginès sąveikos ypatybes, kurios negali būti nusakomos iprastiniais euristiniais metodais (Tucker et al., 2004). Visu tyrimo duomenuc, o ne atskiru duomenų momentu vertinimas yra perspektyvus, nes vertinama ypatybių poreiškio visuma (Poderys, 2004; Torrents, Balague, 2006).

Tepingo testo metu registruojama piršto judesių seka - laiko eilute, iš kurios galima sudaryti šių duomenu informatyviuosius vektorius, t. y. atlikti taip vadinamą duomenų grupavimą - ivairaus dydžio dèmenų skirstymą i grupes. Todèl šio tyrimo metu panaudodami atitinkamus fraktalinès geometrijos dimensijos įverčius (koreliacinès dimensijos įverti, kitaip dar vadinamą plokštumos padengimo koeficientu (PPK)), norime išsiaiškinti, kuo skiriasi sportininko CNS ypatybès prieš fizinị krūvị ir po jo. Tyrimo tikslas - nustatyti duomenu grupavimo metodo panaudojimo galimybę norint išsamiau ịvertinti Tepingo testo metu registruojamų duomenų seka.

\section{METODIKA}

Tyrimai atlikti Lietuvos kūno kultūros akademijos (LKKA) Kineziologijos laboratorijoje. Buvo tiriama 10 asmenų (lengvaatlečių, vidutinių nuotolių bėgiku), kurių amžius $17-25 \mathrm{~m}$. Visi tiriamieji prieš pratybas ir po jų atliko 60 sekundžiu Tepingo testa. Tepingo testo metu tiriamieji nekilnodami riešo turèjo atlikti kiek galima daugiau kompiuterio mygtuko paspaudimų dominuojančios rankos pirštu. Rezultatai buvo registruojami specialia kompiuterine programa, kuri užrašinèjo laiko intervalus tarp dviejų atskirų mygtuko spustelèjimų. Ši speciali CNS darbingumo ir funkcinès būklès kompiuterinè programa sukurta ir patobulinta LKKA Kineziologijos laboratorijoje pagal Ukrainos kūno kultūros universiteto mokslininkų parengtą CNS funkcinès būklès ir darbingumo rodiklių vertinimo metodiką (Зеленцов, Лобановский, 1998). Tokiu būdu gaunama duomenų seka toliau buvo analizuojama.

Duomenų grupavimas. Turèdami duomenų seką — laiko eilutę:

$\left\{x_{1}, x_{2}, x_{3}, \ldots, x_{n}\right\}$

(čia $x_{1}, x_{2}, x_{3}, \ldots, x_{n}$ - laiko intervalai (matuo- jami milisekundèmis) tarp atskiru kompiuterio klaviatūros spustelèjimų, atliekant Tepingo testą), iš šių duomenų galime sudaryti informatyviuosius vektorius, t. y. atlikti duomenu grupavimą.

Skaičiavimai atliekami pasirenkant grupavimo rūši, t. y. po kiek elementų reikia sugrupuoti, kad gautume naudingą informaciją. Tarkime, informatyvusis vektorius turi būti m-tos eilès, tuomet turèsime tokią vektorių seką:

$$
\begin{aligned}
& \left(x_{1}, x_{2}, x_{3}, \ldots, x_{m}\right)^{\mathrm{T}} \\
& \left(x_{2}, x_{3}, x_{4}, \ldots, x_{m+1}\right)^{\mathrm{T}}, \\
& \left(x_{3}, x_{4}, x_{5}, \ldots, x_{m+2}\right)^{\mathrm{T}}, \ldots, \\
& \left(x_{k}, x_{k+1}, x_{k+2}, \ldots, x_{m+k-1}\right)^{\mathrm{T}}, \text { kai } m+k-1=n
\end{aligned}
$$

(čia $\mathrm{n}$ - duomenų skaičius).

Turimus vektorius galime atitinkamai pažymèti:

$$
X_{1}=\left[\begin{array}{c}
x_{1} \\
x_{2} \\
x_{3} \\
\vdots \\
x_{m}
\end{array}\right], X_{2}=\left[\begin{array}{c}
x_{2} \\
x_{3} \\
x_{4} \\
\vdots \\
x_{m+1}
\end{array}\right], X_{3}=\left[\begin{array}{c}
x_{3} \\
x_{4} \\
x_{5} \\
\vdots \\
x_{m+2}
\end{array}\right], \ldots, X_{l}=\left[\begin{array}{c}
x_{k} \\
x_{k+1} \\
x_{k+2} \\
\vdots \\
x_{m+k-1}
\end{array}\right]
$$

Taigi gauname naujus duomenis - vektorius, su kuriais galime atlikti įvairius skaičiavimus.

Šio tyrimo metu naudojamas toks vektoriu „skirtumo“ ivertis:

$\left|X_{i}+X_{j}\right|=\sqrt{\left(x_{i 1}-x_{j 1}\right)^{2}+\left(x_{i 2}-x_{j 2}\right)^{2}+\ldots+\left(x_{i m}-x_{j m}\right)^{2}}$,

kai $X_{i}=\left[\begin{array}{c}x_{i 1} \\ x_{i 2} \\ x_{i 3} \\ \vdots \\ x_{i n}\end{array}\right]$

Pasinaudodami koreliacinès dimensijos formule:

$$
\begin{aligned}
& C(\varepsilon)=\lim _{\varepsilon \rightarrow 0} \frac{1}{N^{2}} \sum_{\substack{i, j=1 \\
i \neq j}}^{N} H\left(\varepsilon-\mid X_{i}-X_{j}\right), \\
& \text { kai } H(x)=\left\{\begin{array}{lc}
0, & x<0 \\
1 / 2, & x=0 \\
1, & x>0,
\end{array}\right.
\end{aligned}
$$

bet neapskaičiuodami ribos, gauname koreliacinès dimensijos įvertį:

$$
C(\varepsilon)=\frac{1}{N^{2}} \sum_{\substack{i, j=1 \\ i \neq j}}^{\infty} H\left(\varepsilon-\mid X_{i}-X_{j}\right)
$$

Parinkę specialias reikšmes $\varepsilon$, gauname $\mathrm{C}(\varepsilon)$ reikšmių seką. Norint gauti kuo daugiau informacijos, parametrai $\varepsilon$ atrinkti eksperimento būdu. 
Šiuo konkrečiu atveju duomenų eilutę sudaro laiko intervalai: $\{162,153,164,154,176,166$, $155,165,154,165, \ldots, 197,199,218,285\}$ (iš viso - 298 duomenys). Tarkime, norime gauti informatyviuosius vektorius, kuriu kiekvienas turès po keturias koordinates, t. y. grupuojama po keturis intervalus, tada:

$X_{1}=\left[\begin{array}{l}162 \\ 153 \\ 164 \\ 154\end{array}\right], X_{2}=\left[\begin{array}{l}153 \\ 164 \\ 154 \\ 176\end{array}\right], X_{3}=\left[\begin{array}{l}164 \\ 154 \\ 176 \\ 166\end{array}\right], \ldots, X_{293}=\left[\begin{array}{l}209 \\ 197 \\ 199 \\ 218\end{array}\right], \ldots, X_{294}=\left[\begin{array}{l}197 \\ 199 \\ 218 \\ 285\end{array}\right]$

Tyrimo duomenys dar buvo grupuojami po 2, 3 ir 5 laiko intervalus. Sugrupuoti duomenys vektoriai, panaudojami koreliacinès dimencijos iverčiams skaičiuoti ir ju priklausomybei nuo parametro $\varepsilon$ nustatyti.

Statistika ir rezultatų vertinimas. Vertinant gautus duomenis, buvo naudojamas matematinès programinès irangos paketas „Mathcad“ (koreliacinès dimensijos įverčiui skaičiuoti), universali programavimo kalba „C++ Builder“, kuria buvo atlikta išsamesnė duomenų analizè (programa apskaičiuoja koreliacinès dimensijos įverti, prieš tai atlikusi duomenu grupavimą ir pateikia rezultatą grafiškai), o statistinès analizès sistema SAS apskaičiuojame koeficientus, nusakančius gautąsias funkcines priklausomybes (Elliot Rebeca, 1999; Blonskis ir kt., 2002, 2004; Vidžiūnas, 2002; Čekavičius ir kt., 2004; Tucker et al., 2004). Norèdami gauti naudingos informacijos ir iqvertinti gautus duomenis, juos grupavome po $2,3,4,5$ laiko intervalus.

\section{REZULTATAI}

Didieji smegenų pusrutuliai, kaip aukščiausias organizmo santykių su aplinka palaikymo organas, yra pastovus organizmo vykdomų funkcijų kontrolierius (Shephard, 1987; Taylor et al., 1996). CNS siunčiamos komandos lemia raumenu pastangu dydi, judesių dažnio kaitą ir kitus tarpraumeninès koordinacijos ypatumus (Skurvydas, 1991; Taylor et al., 1996). Todèl CNS darbingumo ir funkcinès būklès pokytis visada matomas iš raumenų veiklos rodikliu (Shephard, 2001; Busso et al., 2002; McCarthy et al., 2002). Ši glaudi CNS ir raumenu funkciju sąveika yra labai reikšminga atliekant fizinius pratimus, todèl turi būti vertinama valdant sportinès treniruotès vyksma.

Šio tyrimo duomenų rezultatai parode, kad Tepingo testo duomenu grupavimas atskleidžia naujas CNS funkcijos ypatybes, leidžia naujai ivertinti gautų tyrimo rezultatų visumą. Visgi duomenu sekos grupavimo dydžio pasirinkimas, t. y. po kiek elemetu reikia grupuoti, kad būtų galima gauti reikiamą informacija, yra labai svarbus.

Pirmame paveiksle pateikta koreliacinès dimensijos priklausomybè nuo $\varepsilon$, antrame - koreliacinès dimensijos įverčio priklausomybè nuo $\varepsilon$, grupuojant po du intervalus. Matome, kad parinkę tam tikrus $\varepsilon$ gauname funkcinę išraišką $C(\varepsilon)$. Parametrai $\varepsilon$ atrinkti eksperimento būdu, norint gauti kuo daugiau informacijos. Šiuo atveju $\varepsilon$ kinta 1,888 žingsniu nuo 1,35 iki 18,342. Gauti visų tiriamujų rezultatai yra panašūs.

Turèdami koficientu C $(\varepsilon)$ seką, gauname naują informaciją apie tiriamo asmens individualių CNS ypatybių poreiškio visumą, realizuojant

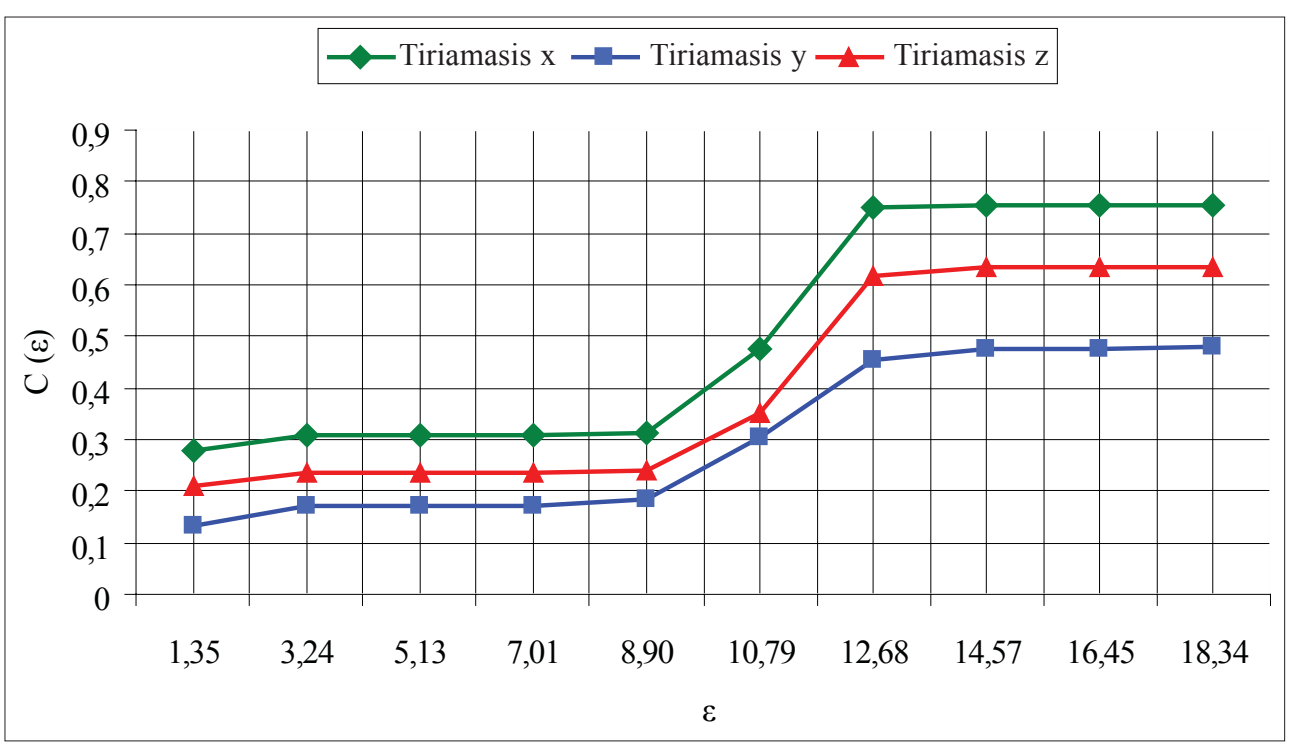

1 pav. Koreliacinès dimensijos îverčio priklausomybẻ nuo $\varepsilon$ prieš fizinị krūvị 
2 pav. Koreliacinès dimensijos įverčio priklausomybė nuo $\varepsilon$, kai prieš fizinị krūvị grupuojami trys piršto judesio intervalai
3 pav. Vieno tiriamojo koreliacinès dimensijos įverčio priklausomybè nuo $\varepsilon$ prieš fizinị krūvị ir po jo
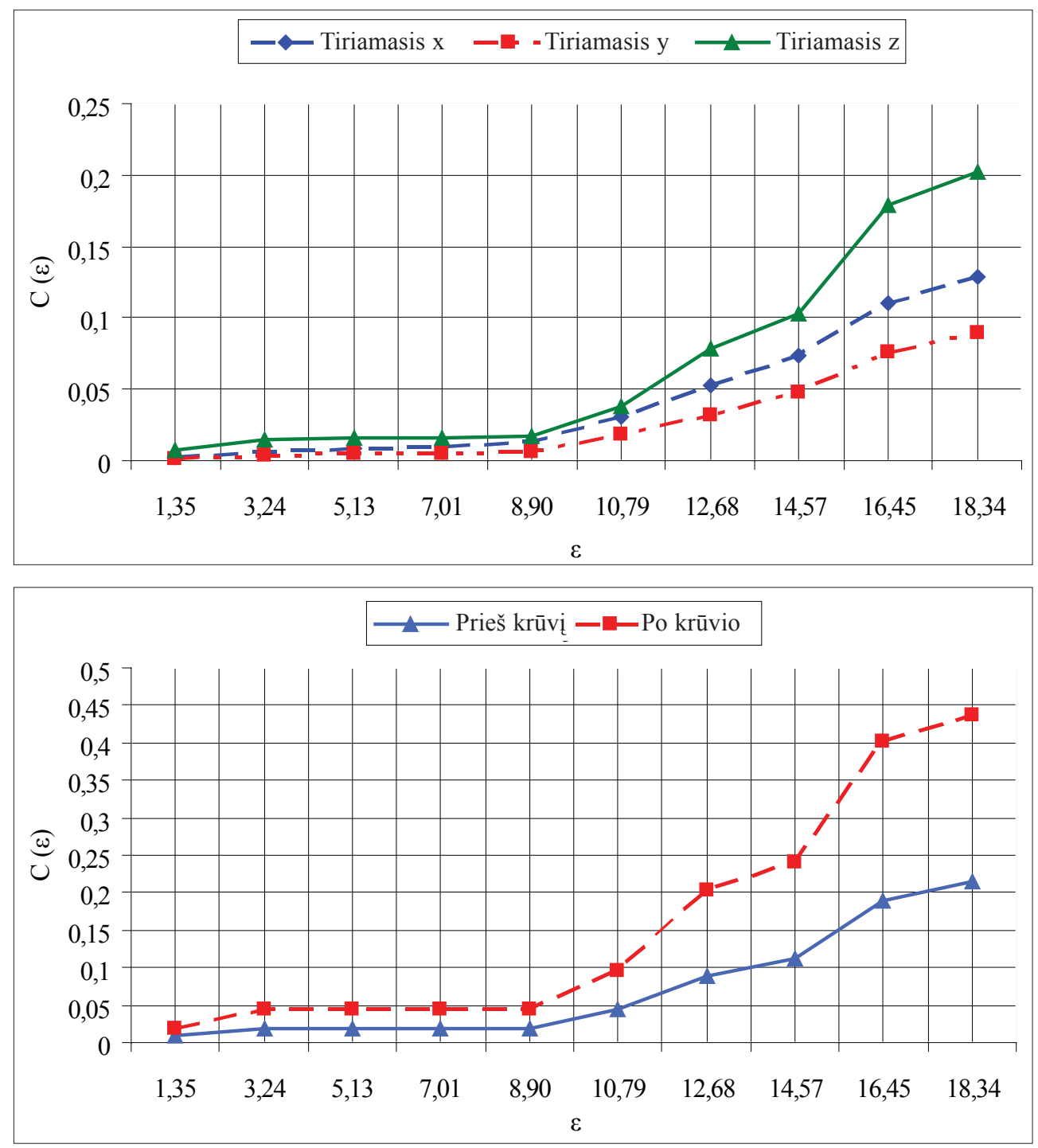

motorinius vyksmus (šiuo atveju Tepingo testo užduoti), taip pat galime palyginti ir grupuojamu intervalų rezultatus.

Visgi gautieji koreliacinès dimensijos įverčiai nèra pakankamai informatyvūs, t. y. visų tiriamuju panašūs. Todèl norèdami tiksliau įvertinti gautu duomenų tarpusavio panašumus ir skirtumus naudojome kitoki duomenų grupavimą. Šio vertinimo rezultatai parode, kad geriausias rezultatas pasiekiamas tada, kai grupuojama po tris intervalus (2 pav.). Matome, kad, kol $\varepsilon$ kinta nuo 1,35 iki 8,902 , grafikai tarpusavyje mažai skiriasi, tačiau vèliau pastebime reikšmingą skirtumą $(\mathrm{p}<0,05)$.

Vertindami tyrimo rezultatus, gautus prieš treniruotę ir po jos, t. y. sportininkui esant nuovargio būsenos, nustatème, kad toks Tepingo testo rezultatų vertinimas rodo i̇vykusius CNS būsenos pokyčius ir leidžia vertinti kiekvieno tiriamojo CNS būsenos pokyčio dydị. Tiriamojo Tepingo testo rezultatų prieš pratybas ir po jų îvertinimas pateiktas trečiame paveiksle. Iš jo matyti skirtumas tarp dviejų vertinimo rezultatų (3 pav.). Visais atvejais ivverčio priklausomybès nuo $\varepsilon$ grafikuose (tiriamuju po pratybu) matyti staigesnis kilimas, o gaunamos koreliacinès dimensijos įverčių reikšmès pastebimai didesnès. Todèl galima daryti prielaidą, kad pagal šias priklausomybių funkcijas imanoma nustatyti sportininkų individualius rodiklius prieš pratybas ir po jų.

\section{REZULTATU APTARIMAS}

Atliekant fizinius pratimus ypač svarbi CNS, kurios funkcija užtikrina intensyviai dirbančio organizmo homeostazę ir saugo ji nuo persitempimo. Sudètingu judesių kokybè priklauso nuo smegenų gebejjimo keistis ir prisitaikyti prie fizinio krūvio intensyvumo bei metabolinių poreikių, siųsti reikiamas komandas atitinkamam motoriniu griaučių raumenų vienetų kiekiui — rekrutuojant juos 
pratimu metu (McCarthy et al., 2002; Noakes, St Clair Gibson, 2004). Taigi aktuali sporto mokslo problema - kaip surasti būdus, leidžiančius tiksliau ivvertinti šias CNS funkcijos ypatybes, ir kaip ivertinti CNS funkcijos ypatybiu pokyčius dèl pratybų krūvio (Noakes, St Clair Gibson, 2004).

Individualizavimo principo reikšmę pabrèžia daugelis autorių (Shephard, 2001; Busso et al., 2002; McCarthy et al., 2002) pažymėdami, kad jis yra labai svarbus tiek vertinant sportuojančių asmenų funkcinių tyrimų rezultatus, tiek parenkant pratybų priemones ir fizinius krūvius. Sporto praktikai reikalingi tyrimai, leidžiantys išskirti individualius ypatumus. Taip pat svarbu įvertinti tyrimo rezultatų visumą (Torrents et al., 2006). Apibendrinant šio tyrimo rezultatus galima pažymèti, kad taikant klasikinès statistikos metodus ir lyginant duomenis tarpusavyje daugeliu atveju susiklosto labai panaši situacija. Todèl sunku gauti reikšmingą informaciją apie tiriamo asmens individualių CNS ypatybiu poreiškio visumą. Duomenų grupavimo metodas leidžia išsamiau vertinti tyrimo rezultatus ir atskleidžia ivvairių fiziologiniu mechanizmu sąveikos ypatybes. Tepingo testo metu duomenys šiuo metodu grupuojami po 2, 3, 4, 5 ir daugiau intervalu. Tyrimo metu gautus duomenis grupuojant po du intervalus, vertinimo rezultatai nèra pakankamai informatyvūs. Grupuojant po tris intervalus - mažesnis rezultatų išsibarstymas, ir tai leidžia efektyviau panaudoti duomenis ir atitinkamai daryti tikslesnes išvadas apie pratybu poveiki CNS funkcijai. Tepingo testo duomenis grupuojant po keturis ar daugiau intervalu, gaunami neinformatyvūs rezultatai.

\section{IŠVADOS}

1. Duomenu grupavimo metodo panaudojimas išplečia tyrèjo galimybes, leidžia nuodugniau ir tiksliau įvertinti CNS ypatybiu poreiškị Tepingo testo metu.

2. Grupuojant po du judesio laiko intervalus, Tepingo testo rezultatai nèra tiksliausi. Išsamesnè informacija apie CNS ypatybes, pasireiškiančias Tepingo testo metu, teikia duomenu grupavimo metodas, kai sujungiami trys tiriamojo piršto judesių intervalai. Grupuojant po keturis ir daugiau intervalų — rezultatų informatyvumas sumažèja.

\section{LITERATŪRA}

Blonskis, J., Bukšnaitis, V., Končienė, J., Rubliauskas, D. (2002). C++ Praktikumas. Kaunas.

Blonskis, J., Bukšnaitis, V., Misevičius, A., Rubliauskas, D. (2004). C++ Builder grafika. Kaunas.

Busso, T., Benoit, H., Bonnefoy, R., Feasson, L., Lacour, J. R. (2002). Effects of training frequency on the dynamics of performance response to a single training bout. Journal of Applied Physiology, 92 (2), 572-580.

Čekanavičius, V., Murauskas, G. (2004). Statistika ir jos taikymai. Vilnius.

Elliott, R. J. (1999). Learning SAS in the Computer Lab. Kanada.

Emeljanovas, A., Poderytė, K., Poderys, J. (2003). Sportinių žaidimų ir ciklinių sporto šakų treniruočiu įtaka vaikų centrinės nervų sistemos darbingumo ir funkcinès būklès rodikliams. Ugdymas. Küno kultūra. Sportas, 3 (48), 21-25.

McCarthy, J. P., Pozniak, M. A., Agre, J. C. (2002). Neuromuscular adaptations to concurrent strength and endurance training. Medicine and Science in Sports and Exercise, 34 (3), 511-519.

Noakes, T. D., St Clair Gibson, A. (2004). Logical limitations in the "catastrophe" models of fatigue during exercise in humans. British Journal of Sports Medicine, $38,648-649$.

Poderys, J. (2004). Judesių fiziologiniai ir biocheminiai pagrindai. Kineziologijos pagrindai, 146-155.
Shephard, R. J. (2001). Absolute versus relative intensity of physical activity in a dose-response context. Medicine and Science in Sports and Exercise, 33 (Suppl. 6), 400418, 419-420.

Shephard, R. J. (1987). Exercise Physiology. Toronto Philadelphia: B. C. DECKER INC.

Skurvydas, A. (1991). Organizmo adaptacijos prie fiziniu krūviu pagrindiniai désningumai. D. II. Vilnius. P. 4-17.

Taylor, J. L., Butler, J. E., Allen, G. M., Gandevia, S. C. (1996). Changes in motor cortical excitability during human muscle fatigue. Journal of Physiology, 15, 490, $519-528$.

Torrents, C., Balagué, N. (2006). Dynamic systems theory and sports training. Ugdymas. Küno kultūra. Sportas, 1 (60), 72-84.

Tucker, W. T., Ferson, S., Oberkampf, W. L. (2004). The Notion of Independence when Probabilities are Imprecise. Paper presented at the $9^{\text {th }}$ ASCE Specialty Conference on Probabilistic Mechanics and Structural Reliability, Albuquerque, NM, July 26-28.

Vidžiūnas, A. (2002). $C++$ ir $C++$ Builder pradmenys. Kaunas.

Зеленцов, А. М., Лобановский, В. В. (1998). Моделирование трениротовки в футболе. Киев. 


\title{
FINGER TAPPING TEST MOVEMENT ANALYSIS BY METHOD OF NONLINEAR DIMENSIONAL REDUCTION
}

\author{
Laura Daniusevičiūtè ${ }^{1,2}$, Zenonas Navickas², Jonas Poderys ${ }^{1}$, Marius Brazaitis ${ }^{1}$, \\ Irina Ramanauskien $\dot{e}^{1,2}$ \\ Lithuanian Academy of Physical Education ${ }^{1}$, Kaunas University of Technology ${ }^{2}$, Kaunas, Lithuania
}

\begin{abstract}
Finger Tapping Test and other performance based tests are widely used in the assessment of the functional state of the central nervous system.

The aim of the study was to assess the Tapping Test data by method of nonlinear dimensional reduction (by grouping them to various components). The study was performed in the Laboratory of Human Kinetics at the Lithuanian Academy of Physical Education. The finger movements data were registered by using a special computer program, created in the laboratory of Kinesiology, Lithuanian Academy of Physical Education. The subjects of the study were 10 athletes aged $12-25$ years. All the subjects did a clasical 60 seconds Finger Tapping Test, and the time intervals of each finger movement were recorded in milliseconds.

All the subjects took part in two investigations: before and after an exhausting training session. The method of nonlinear dimensional reduction of data was created in Kaunas University of Technology in the Department of Applied Mathematics. The results obtained during the study showed that the correlation index helped to get new information about the peculiarities of the central nervous system of the subjects, actualizing the motor acts, and we could also compare different experemental groups.

In conclusion we can to point out that the method of nonlinear dimensional reduction allows us to obtain new information about the peculiarities of functioning of the central nervous system. The most sensitive changes can be obtained in case of grouping three intervals. The data become less informative if we use the grouping of two intervals. Using four or more intervals for grouping makes the information more superficial again.
\end{abstract}

Keywords: method of nonlinear dimensional reduction, central nervous sytem, Finger Tapping test.

Gauta 2006 m. rugsèjo 12 d.

Received on September 12, 2006

Laura Daniusevičiūtè

Kauno technologijos universitetas

(Kaunas University of Technology)

K. Donelaičio g. 73, LT-44029 Kaunas

Lietuva (Lithuania)

Tel +37060065490

E-mail lauruka@yahoo.com 